Review

\title{
New Ways of Working and Public Healthcare Professionals' Well-Being: The Response to Face the COVID-19 Pandemic
}

\author{
M. Ángeles López-Cabarcos ${ }^{1, *}$, Analía López-Carballeira ${ }^{1}$ and Carlos Ferro-Soto ${ }^{2}$ D \\ 1 Department of Business Administration, Faculty of Business Administration, \\ Santiago de Compostela University, 15705 Santiago de Compostela, Spain; analia.lopez.carballeira@usc.es \\ 2 Department of Business Administration, Faculty of Business Administration, Vigo University, 36310 Vigo, \\ Pontevedra, Spain; cferro@uvigo.es \\ * Correspondence: angeles.lopez.cabarcos@usc.es
}

Received: 29 August 2020; Accepted: 28 September 2020; Published: 30 September 2020

\begin{abstract}
This research proposes analyzing the influence of new ways of working (NWW) on healthcare professional's well-being and how these may affect work performance and public service motivation. These variables and relationships were important before COVID-19 pandemic, and everything points to the fact that during and after the pandemic their importance will be higher. To buffer the potential negative effects of implementing the NWW, both organizations and employees must identify personal (psychological capital) and job resources (inter-role conflict, psychological empowerment, meaning of work) capable of acting as effective moderators to promote employee well-being and avoid negative experiences at work. This paper aims to shed light on new ways of coping and adapting to uncertain job requirements such as those that have arisen during COVID-19. Moreover, it highlights the great changes that public healthcare needs to face to improve the quality of the service offered to society. It is urgent that public administrators and human resources managers design effective strategies and make effective decisions in which employee well-being and service quality are main priorities.
\end{abstract}

Keywords: public healthcare; new ways of working; employee well-being; COVID-19 pandemic

\section{The Influence of NWW on Employee Well-Being}

The COVID-19 pandemic decreed by the World Health Organization has forced public administrations to adopt drastic measures regarding timing and ways of working. Social distancing, self-isolation or mobility restrictions to protect citizens have also made full sense at the workplace. The response to face the COVID-19 represents an extraordinary challenge for the public sector and the public healthcare system, which must propose and implement obligatory, flexible and innovative ways of working to protect employees and the entire society.

New ways of working (NWW) refers to the process of designing the work in which employees can control the timing and place to work based on new technologies [1]. In other words, NWW are aimed to provide employees the necessary flexibility and freedom to determine how, where and when they can work, using new technological advances [2-4]. In the context of the collective fight against COVID-19, public healthcare professionals, namely medical and nursing staff whose work is directly aimed at improving the health of patients, have been forced to adopt NWW that have lead them to work from home, or at least from places other than the workplace, requiring adaptation to carry out flexible, online and virtual tasks. In this sense, telemedicine and e-health using virtual software platforms through information and communication technologies have been able to deliver remote care and health assessment to patients both infected with COVID-19 or not [5,6]. The COVID-19 outbreak has 
significantly changed the way of working in the public healthcare system, accelerating the widespread use of remote healthcare approaches such as the telephone, video-based consultations and new virtual software platforms to avoid in-person consultations and prevent the spread of the infection.

NWW have a decisive influence on how work is understood and, what is more important, on the working conditions. In this sense, NWW mean a huge change in relation to the relationship between public employees and their work; namely, where and how public employees carry out their work, the demands of the work on them, and the demands the employees face outside their jobs [2,7]. Thus, the flexibility to organize the work can have a great influence on the behaviors of employees and may lead to both negative situations that affect their well-being and performance, or, conversely, very positive experiences at work that result in higher well-being, performance and service quality $[1,8]$. In public healthcare, NWW based on new technologies may allow employees to carry out their job without physical interactions among them or with patients and their families, helping to achieve in this way the goal of keeping the proper social distance. At this point, it is important to analyze the potential effects of NWW both on public healthcare workers and on the functioning of the public healthcare system.

The characteristics of the public sector can lead employees to suffer negative experiences at work, particularly in the specific context of public healthcare [9]. Public healthcare professionals are under high levels of pressure because they must carry out their work allocating scant resources to equally needful patients, providing care for all severely unwell patients, balancing their own physical and mental healthcare needs with those of the patients, and aligning their desires and duties with those of the patients' family and friends [10]. This pressure has significantly increased due to the occurrence of the COVID-19 pandemic. Moreover, the rigid structure of public healthcare organizations can make it very difficult for healthcare professionals to show the necessary flexibility they need to carry out their tasks in many cases [11]. All these reasons make these professionals more vulnerable to suffer negative experiences at work like emotional exhaustion, which relates to feelings of fatigue, irritability and frustration, and wearing out or depleting the emotional resources of the employee [12]. The very nature of health work, together with the global fight against COVID-19, has intensified the risk of suffering emotional exhaustion. To the harsh working conditions are now added the risk of infection of themselves, their colleagues, their patients and families, or some member of their families or group of friends $[13,14]$. The implementation of NWW as a response to COVID-19 may help increase the risk of suffering emotional exhaustion as a result of the informational overload, the interruptions, the misunderstandings, the necessity of being continuously connected or the lack of support from colleagues and superiors [2,7]. Moreover, medical care based on diagnoses without physical examinations, together with the lack of training in new technologies and the resistance to change of both healthcare professionals and patients, can seriously damage the quality of the healthcare professionals' work, leading them to be emotionally exhausted.

Given the speedy implementation of NWW due to the situation generated by COVID-19, it is urgent to review the preparation of recommendations, policies and practices related to ensuring appropriate and safe remote workplaces, providing at the same time training in the use of technical equipment and virtual collaborative environments [7]. In sum, the special nature of public healthcare together with the emergence of NWW can lead employees to be emotionally exhausted. To date, no research has analyzed the effect of NWW on emotional exhaustion among public healthcare professionals.

The fight against the COVID-19 pandemic can lead public healthcare professionals to be emotionally exhausted, but also develop strong bonds with their work, strengthening its vocational nature and wishing to develop it with more energy and willingness. In fact, public healthcare can be understood mostly as a vocational profession since employees are expected to be willing to do something meaningful, help others and serve to the public interests [15]. In this sense, the main aim of the public healthcare professionals is promoting health, whereby the quality of care and patient safety are the main priorities [16]. Considering both the public and vocational natures of the work of healthcare professionals, it seems reasonable to think that they can feel their profession as a challenge able to 
promote very positive experiences that lead them to engage with their work and the public interest. Engaged employees develop "a positive, fulfilling work related state of mind that is characterized by vigor, dedication and absorption" (p. 74) [17]. Thus, extreme situations such as the COVID-19 pandemic and the rapid implementation of NWW can stimulate employees to make more efforts to carry out their job (challenging job demand), engaging them in their work and duties even more than in 'normal' situations [18]. Furthermore, always, but to a greater extend in the COVID-19 context, providing public healthcare employees more flexibility around their work combined with adequate and agile communication technologies can help them be more proactive, take responsibility for their own professional development and be enthusiastically involved with their work [2,7]. Some previous research has concluded the positive relationship between the flexibility derived from some NWW and employee work engagement $[8,19]$, however more research is needed considering other aspects beyond flexibility and the high number of different situations derived from the new work contexts.

There are many work environments in which the workplaces are not completely safe, technical equipment are not always guaranteed or collaborative communication is poor [7], especially in public healthcare where the pressure and work rate is huge mainly in periods like the COVID-19 pandemic, and thus the well-being of employees may be negatively affected both physically and psychologically [20]. Conversely, work environments characterized by autonomy, flexibility and adequate communication practices [2,7] can lead public professionals to commit to their work, enjoying in turn better physical and psychological health. As NWW can significantly influence the work environment and an employee's well-being, much more research is needed to analyze the sense and significance of this influence and the implications on people's lives and service quality. According to job demands-resources theory [21], NWW can be considered both a job resource and a job demand depending on their positive or negative potential effects. Precisely, this fact justifies the need to analyze exhaustively its influence and effects on employee well-being. As a job demand, NWW can spark a stressful process that may-via burnout-lead to the development of negative experiences at work that negatively influence employee physical and psychological health. Conversely, as a job resource, NWW can spark a motivational process that may-via engagement-lead to the development of positive experiences at work that influence positively employee physical and psychological health [22]. To date, no research has analyzed the mediating role of emotional exhaustion and work engagement in the relationship between NWW and employee well-being in the specific study context of public healthcare. This fact, together with the great relevance and complexity of the work of public healthcare professionals and the still uncertain consequences of the COVID-19 pandemic, justifies the need for much more scientific research in this field. Figure 1 shows the proposed model I.

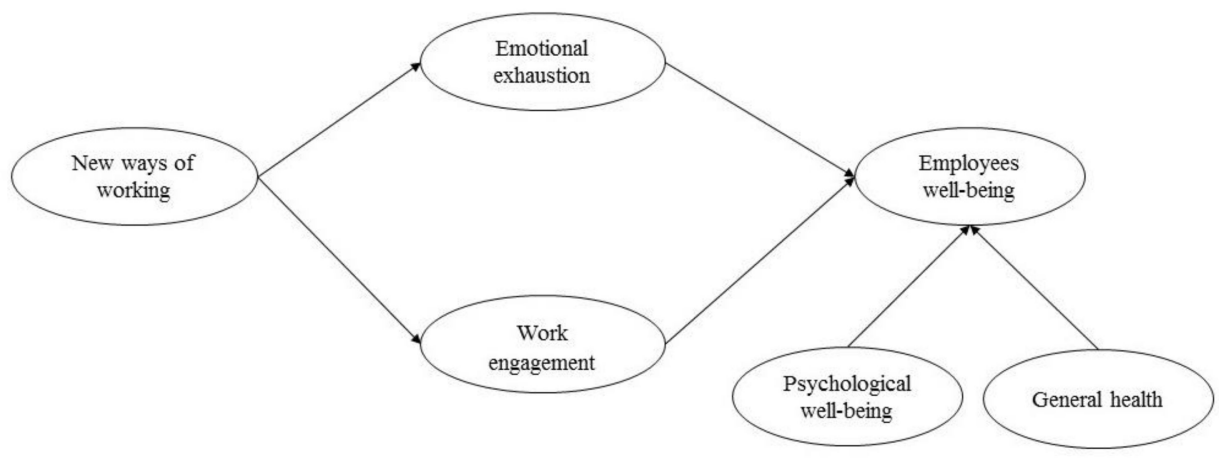

Figure 1. Proposed model I.

\section{The Influence of Employee Well-Being on Their Performance and Public Service Motivation}

The advancement of knowledge around the implications of NWW is also justified by the fact that the physical and psychological well-being of public healthcare professionals is the cornerstone of every 
well-functioning healthcare system [14], affecting job performance [23,24], service quality and public service motivation. Factors like the distribution of work shifts, caring for a large number of patients in short spaces of time, intense working days, shortage of staff or the lack of means to draw up effective treatments and diagnoses $[10,14]$ make public healthcare a very complex environment in which to work, and more so in the COVID-19 context. In this sense, low mood, sleep problems, low levels of concentration or the potential risk of infecting or being infected can lead public healthcare professionals to carry out their work under poor conditions, increasing their insecurity and consequently the possibility of making more errors [14,25]. All of this can lead to lower performance levels and lower employee motivation. On the contrary, being positive, keeping healthy and with a balanced state of mind can help employees do their job successfully, be more proactive, help patients or colleagues that require assistance, or seek solutions to regulate the flow of patients [26]; all of which leads in turn to higher performance levels and higher employee motivation.

Performance (in-role behavior) can be defined as what is required or expected as part of the duties and responsibilities formally assigned to the work of the employees [27]. The pressure of the COVID-19 pandemic, the complexity of healthcare work and the uncertainties around NWW can affect the service quality offered to patients and the employee well-being, affecting at the end the effectiveness with which employees must carry out their formally-prescribed job tasks. In the same way, those extra-role behaviors that go beyond the formalized requirements of work [27] and that are so important for the proper functioning of public healthcare through the promotion of voluntary cooperative behaviors [28] can also be seriously affected, making it difficult to shape informal organizational structures among healthcare professionals. Public service motivation refers to an individual's predisposition to respond to motives grounded primarily or uniquely in public institutions [29]. Thus, employees in public service motivated are altruistic and they do not expect reciprocity from the recipients of their services [30,31]. In this sense, public servants with high levels of service motivation focus their available energy and dedication on the public good on a daily basis [15]. Public healthcare professionals serve other people through the delivery of public services, so they must devote all their energies and efforts to perform their tasks in the best way for the entire society. In this sense, public healthcare workers with good physical and psychological health can increase their levels of public service motivation, reinforcing the belief that work is pleasurable and meaningful [15], which in turn can lead them to improve the quality of the service offered. However, low levels of health or psychological well-being can lead public healthcare workers to have less desire to help others [15], affecting in this way their service motivation and consequently the service quality, the effectiveness of the healthcare system and the well-being of the entire society. According to the conservation of resources theory [32], employees who show lack of resources to develop their work are more vulnerable to the experience of loss spirals, while those employees with ample resources have more opportunities to obtain new ones. Thus, public healthcare professionals who do not have sufficient energy to do their work correctly try to conserve their energies, reaching minimum performance requirements. Conversely, public healthcare professionals who have sufficient energy to do their work correctly are capable of creating new and better opportunities for establishing positive experiences at work. Despite the great relevance and implications of these variables, to date no research has analyzed the effect of employee physical and psychological well-being on their performance and service motivation in the specific study context of public healthcare. Figure 2 shows the proposed model II. 


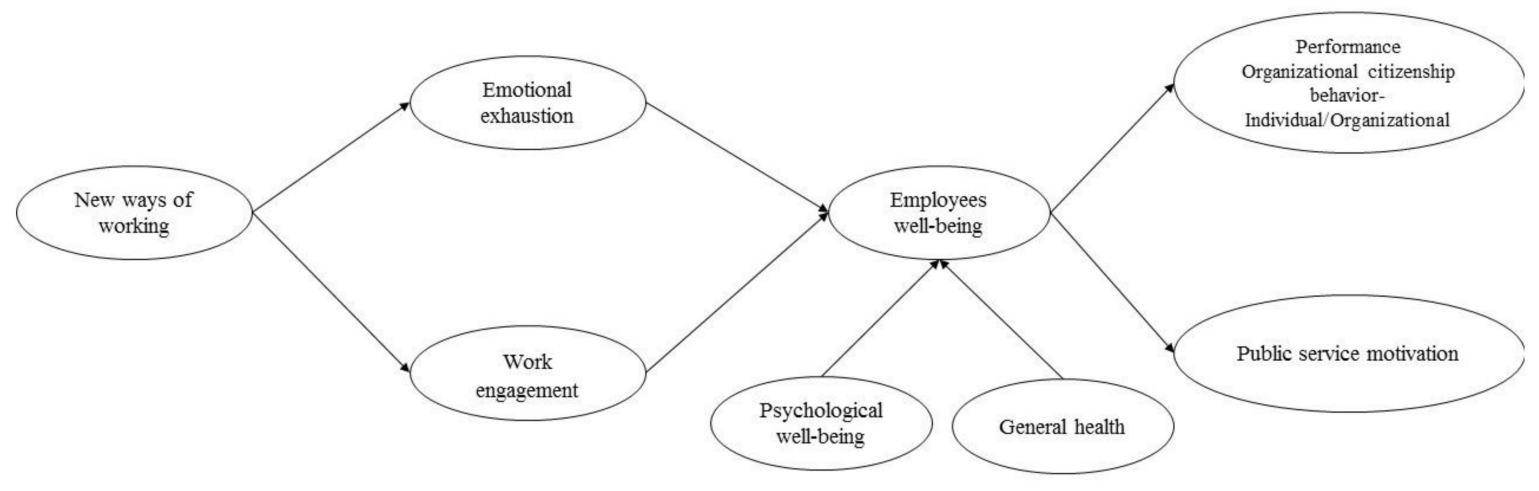

Figure 2. Proposed model II.

\section{The Moderating Role of Employee Psychological Capital, Inter-Role Conflict, Psychological Empowerment and the Meaning of Work}

At this point, what seems clear is that NWW can both hinder and promote the work of public healthcare professionals, leading them, depending on the case, to either be emotionally exhausted or engaged in their work. The COVID-19 work context is forcing healthcare professionals to resort to personal resources to cope with and adapt to an increasingly uncertain and complex work environment. Precisely, employee psychological capital, which refers to the positive psychological state of development characterized by self-efficacy, optimism, hope, and resilience [33,34], can help employees mobilize their personal resources to develop essential strengths to face the adversities of the work environment $[24,35,36]$. At the same time, the rapid implementation of NWW due to the COVID-19 pandemic may provoke an inadequate work-life balance for employees. In this sense, the inter-role conflict, which is defined as the role pressures from the work and family domains that are mutually incompatible in some respect [37], may also moderate employee emotional exhaustion or, where appropriate, employee work engagement. In the COVID-19 work context, the intense pressure on healthcare professionals and the rapid adoption of NWW may lead healthcare professionals to be unable to simultaneously and effectively fulfill their family and professional responsibilities, seriously affecting their well-being. Thus, maintaining family and work boundaries has become a great challenge for public healthcare professionals, who can see how the results of their efforts can affect their emotional exhaustion (decreasing it) or their work engagement (increasing it). Despite their relevance, to date there is no research analyzing in depth the positive/negative sign and the intensity of the moderating role of employee psychological capital and inter-role conflict. At this point, the issue to be analyzed is the moderating role of both variables in the relationships between NWW and employee emotional exhaustion or employee work engagement in the specific study context of public healthcare.

Likewise, the analysis of the moderating role of psychological empowerment, which refers to a set of psychological states-meaning, competence, self-determination and impact-that are necessary to feel a sense of control in relation to one's work [38] is crucial. Psychological empowerment can help employees make decisions with greater autonomy and flexibility, as well as exert influence regarding work and accomplish tasks in meaningful ways [39,40]. Psychological empowerment makes employees more active in their jobs, helps them improve their job methods and ensure compliance with job objectives in an effective way [41]. In the context of the COVID-19 pandemic, psychological empowerment can help public healthcare professionals provide new tools to cope with the feelings of emotional exhaustion, or reinforce the engagement to their job thereby increasing their well-being. In this sense, psychological empowerment can be viewed as a powerful instrument, able to encourage workers to develop their tasks adequately; since they have the sensation of controlling their work, they have the capacity to perform their assigned tasks and they can positively influence organizational outcomes [42,43]. Thus, psychological empowerment can act as a motivational source in the workplace, improving the level of physical and psychological employee well-being by strengthening engagement 
or buffering feelings of emotional exhaustion. To the best of our knowledge, no research has analyzed the moderating role of psychological empowerment in the relationship between employee emotional exhaustion or employee work engagement and employee well-being in the specific study context of public healthcare.

Meaning of work, which refers to the basic values that employees associate with work such as work content, the meaning of the tasks developed and the visualization of their contribution to service [44], can provide employees the resources needed to value their work [45], improving their performance and service motivation levels [46]. In the context of the COVID-19 pandemic, healthcare professionals must feel that they are members of an organization whose main objective is the quality of the service offered, whereby the meaning of work can help them feel that their work context is significant and purposeful, and lead them to achieve their work goals, stimulating personal growth, learning and development [22]. To the best of our knowledge, no research has analyzed the moderating role of meaning of work in the relationships between employee well-being and employee performance or service motivation in the specific study context of public healthcare.

According to job demands-resources theory, job resources such as employee psychological capital, inter-role conflict or psychological empowerment may act as 'buffers' on the negative relationship between high job demands or low job resources and employee well-being. According to conservation resources theory, the accumulation of resources as meaning of work may lead employees to be more likely to risk these resources to obtain others capable of contributing to the achievement of positive outcomes. The results of this study can surely contribute to the advancement of knowledge around NWW, emotional exhaustion and work engagement, as well as the improvement of the well-being of public healthcare professionals and the quality of the service offered to patients, their families and the entire society. Figure 3 shows the full proposed model.

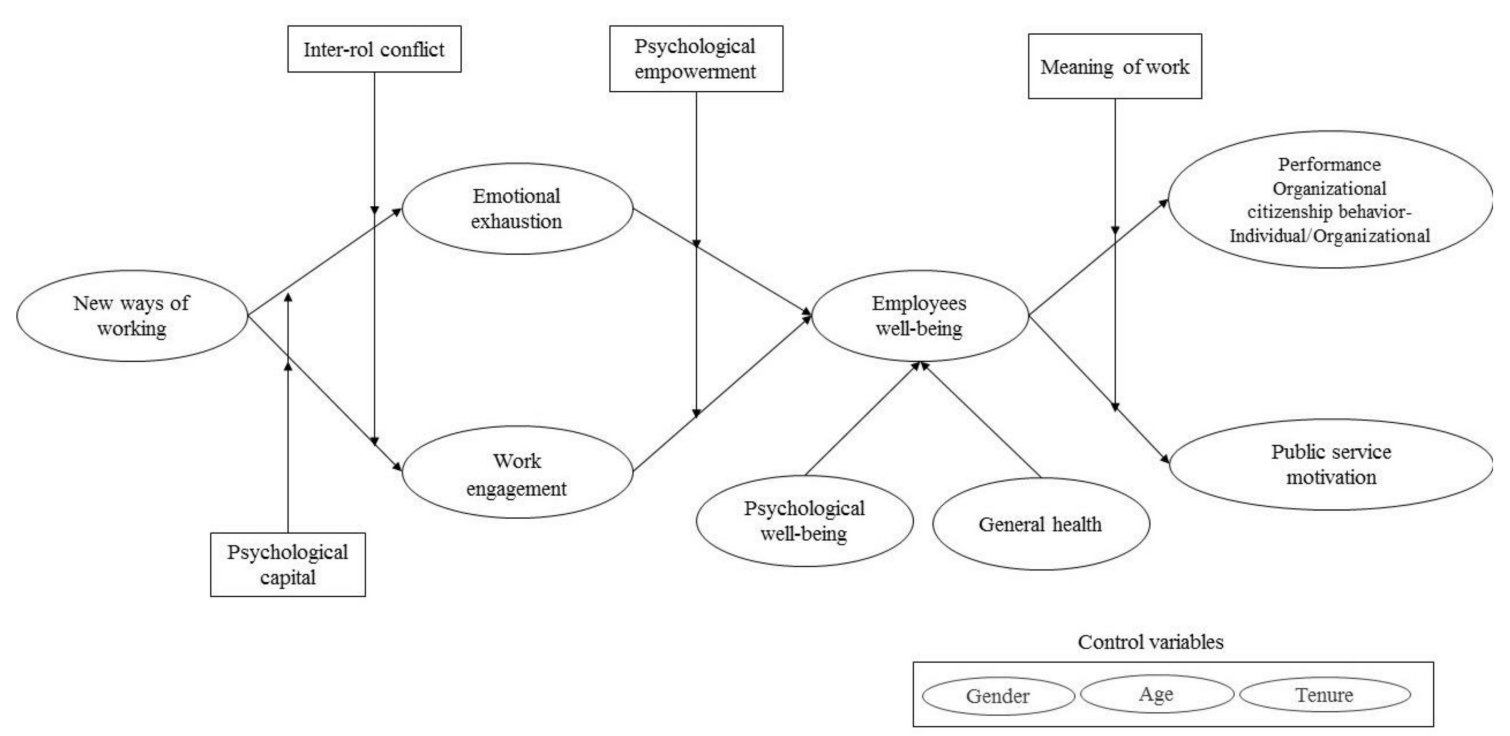

Figure 3. Full proposed model.

\section{Practical Implication and Conclusions}

NWW can be crucial to understand the role of variables such as emotional exhaustion and work engagement and how they can affect the public healthcare system in the future. The challenge posed by public administrations through the incorporation of NWW due to the COVID-19 pandemic may cause huge changes around the work of healthcare professionals. In fact, work environments like the current ones characterized by high volatility, uncertainty and complexity can be an exciting opportunity for encouraging public administrations and healthcare managers to propose innovative formulas related to the way of working and service delivery [47]. In this sense, it is urgent that public 
administrators and human resources managers design effective strategies aimed to adapt NWW as soon as possible to the needs of the employees. More specifically, the drafting of codes of good practices together with protocols for action in the event of COVID-19 outbreaks, or clearly planning the available and necessary resources to carry out the work correctly and safely, can be key actions to face these situations effectively. In addition, providing technological applications to facilitate more effective communication flows with patients and colleagues, or promote virtual collaborative workspaces, may help enhance healthcare professionals' well-being, at the same time increasing the quality of the service offered. Enhancing employee personal resources or providing tools to improve the sense of control, the autonomy, the flexibility and the meaning of work can allow public healthcare professionals to cope with and adapt to job requirements in a better way. Therefore, public healthcare is obliged to focus on stimulating positive experiences in which human resources development, public service quality and employee well-being are main priorities. In any working context, but to a greater extent in a context marked by the COVID-19 pandemic, it is essential to understand the influence of NWW on employee well-being to promote and foster job environments characterized by healthy and happy employees capable of achieving better results at all levels.

Author Contributions: Conceptualization, M.Á.L.-C.; A.L.-C., and C.F.-S.; investigation, M.Á.L.-C.; A.L.-C., and C.F.-S.; resources, M.Á.L.-C.; A.L.-C., and C.F.-S.; writing-original draft preparation, M.Á.L.-C.; A.L.-C., and C.F.-S.; writing-review and editing, M.Á.L.-C.; A.L.-C., and C.F.-S.; visualization, M.Á.L.-C.; A.L.-C., and C.F.-S.; supervision, M.Á.L.-C.; A.L.-C., and C.F.-S. All authors have read and agreed to the published version of the manuscript.

Funding: This research received no external funding.

Conflicts of Interest: The authors declare no conflict of interest.

\section{References}

1. Ten Brummelhuis, L.L.; Bakker, A.B.; Hetland, J.; Keulemans, L. Do new ways of working foster work engagement? Psicothema 2012, 24, 113-120.

2. Demerouti, E.; Derks, D.; Lieke, L.; Bakker, A.B. New ways of working: Impact on working conditions, work-family balance, and well-being. In The Impact of ICT on Quality of Working Life; Korunka, C., Hoonakker, P., Eds.; Springer: Dordrecht, The Netherlands, 2014; pp. 123-141.

3. Duque, L.; Costa, R.; Dias, Á.; Pereira, L.; Santos, J.; António, N. New ways of working and the physical environment to improve employee engagement. Sustainability 2020, 12, 6759. [CrossRef]

4. Kotera, Y.; Correa Vione, K. Psychological impacts of the New Ways of Working (NWW): A systematic review. Int. J. Environ. Res. Public Health 2020, 17, 5080. [CrossRef] [PubMed]

5. Leite, H.; Hodgkinson, I.R.; Gruber, T. New Development: 'Healing at a distance'-Telemedicine and COVID-19. Public Money Manag. 2020, 40, 483-485. [CrossRef]

6. Smith, A.C.; Thomas, E.; Snoswell, C.L.; Haydon, H.; Mehrotra, A.; Clemensen, J.; Caffery, L.J. Telehealth for global emergencies: Implications for coronavirus disease 2019 (COVID-19). J. Telemed. Telecare 2020, 26, 309-313. [CrossRef]

7. Schuster, C.; Weitzman, L.; Sass Mikkelsen, K.; Meyer-Sahling, J.; Bersch, K.; Fukuyama, F.; Paskov, P.; Rogger, D.; Mistree, D.; Kay, K. Responding to covid-19 through surveys of public servants. Public Adm. Rev. 2020. [CrossRef]

8. Gerards, R.; de Grip, A.; Baudewijns, C. Do new ways of working increase work engagement? Pers. Rev. 2018, 47, 517-534. [CrossRef]

9. Lopez-Cabarcos, M.A.; Lopez-Carballeira, A.; Ferro-Soto, C. The role of emotional exhaustion among public healthcare professionals. J. Health Organ. Manag 2019, 33, 649-655. [CrossRef]

10. La Parra-Casado, D.; Mosquera, P.A.; Vives-Cases, C.; San Sebastian, M. Socioeconomic Inequalities in the use of Healthcare Services: Comparison between the Roma and General Populations in Spain. Int. J. Environ. Res. Public Health 2018, 15, 121. [CrossRef] 
11. Montgomery, A.; Todorova, I.; Baban, A.; Panagopoulou, E. Improving quality and safety in the hospital: The link between organizational culture, burnout, and quality of care. Br. J. Health Psychol. 2013, 18, 656-662. [CrossRef]

12. Maslach, C.; Jackson, S.E. The measurement of experienced burnout. J. Occup. 1981, 2, 99-113. [CrossRef]

13. Jnr, B.A. Use of telemedicine and virtual care for remote treatment in response to covid-19 pandemic. J. Med. Syst. 2020, 44, 132. [CrossRef]

14. Moazzami, B.; Razavi-Khorasani, N.; Moghadam, A.D.; Farokhi, E.; Rezaei, N. COVID-19 and telemedicine: Immediate action required for maintaining healthcare providers well-being. J. Clin. Virol. 2020, 126, 104345. [CrossRef]

15. Bakker, A.B. A Job demands-resources approach to public service motivation. Public Adm. Rev. 2015, 75, 723-732. [CrossRef]

16. Shantz, A.; Alfes, K.; Arevshatian, L. HRM in healthcare: The role of work engagement. Pers. Rev. 2016, 45, 274-295. [CrossRef]

17. Schaufeli, W.B.; Salanova, M.; González-Romá, V.; Bakker, A.B. The measurement of engagement and burnout: A two-sample confirmatory factor analytic approach. J. Happiness Stud. 2002, 3, 71-92. [CrossRef]

18. Van den Broeck, A.; De Cuyper, N.; De Witte, H.; Vansteenkiste, M. Not all job demands are equal: Differentiating job hindrances and job challenges in the job demands-resources model. Eur. J. Work Organ. Psychol. 2010, 19, 735-759. [CrossRef]

19. Baudewijns, C.; Gerards, R.; de Grip, A. New Ways of Working and Work Engagement; Research Centre for Education and the Labour Market ROA: Maastricht, The Netherlands, 2015.

20. Gómez-Salgado, J.; Domínguez-Salas, S.; Romero-Martín, M.; Ortega-Moreno, M.; García-Iglesias, J.J.; Ruiz-Frutos, C. Sense of coherence and psychological distress among healthcare workers during the COVID-19 pandemic in Spain. Sustainability 2020, 12, 6855. [CrossRef]

21. Demerouti, E.; Bakker, A.B.; Nachreiner, F.; Schaufeli, W.B. The job demands-resources model of burnout. J. Appl. Psychol. 2001, 86, 499-512. [CrossRef]

22. Bakker, A.B.; Demerouti, E. The job demands-resources model: State of the art. J. Manag. Psychol. 2007, 22, 309-328. [CrossRef]

23. Wright, T.A.; Cropanzano, R. Psychological well-being and job satisfaction as predictors of job performance. J. Occup. Health Psychol. 2000, 5, 84-94. [CrossRef] [PubMed]

24. Wingerden, J.V.; Bakker, A.B.; Derks, D. A test of a job demands-resources intervention. J. Manag. Psychol. 2016, 31, 686-701. [CrossRef]

25. Russo, M.; Buonocore, F.; Ferrara, M. Motivational mechanisms influencing error reporting among nurses. J. Manag. Psychol. 2015, 30, 118-132. [CrossRef]

26. Perreira, T.A.; Berta, W. The object of your affection: How commitment, leadership and justice influence workplace behaviours in health care. J. Nurs. Manag. 2016, 24, E146-E154. [CrossRef] [PubMed]

27. Podsakoff, P.M.; MacKenzie, S.B.; Paine, J.B.; Bachrach, D.G. Organizational citizenship behaviors: A critical review of the theoretical and empirical literature and suggestions for future research. J. Manag. 2000, 26, 513-563. [CrossRef]

28. Xerri, M.J.; Brunetto, Y. Fostering innovative behaviour: The importance of employee commitment and organisational citizenship behaviour. Int. J. Hum. Resour. Manag. 2013, 24, 3163-3177. [CrossRef]

29. Perry, J.L.; Wise, L.R. The motivational bases of public service. Public Adm. Rev. 1990, 50, 367-373. [CrossRef]

30. Bao, Y.; Li, C.; Zhao, H. Servant leadership and engagement: A dual mediation model. J. Manag. Psychol. 2018, 33, 406-417. [CrossRef]

31. Li, C.; Bao, Y. Ethical Leadership and positive work behaviors: A conditional process model. J. Manag. Psychol. 2020, 35, 155-168. [CrossRef]

32. Hobfoll, S.E. Conservation of resources-A new attempt at conceptualizing stress. Am. Psychol. 1989, 44, 513-524. [CrossRef]

33. Luthans, F.; Avolio, B.J.; Avey, J.B.; Norman, S.M. Positive psychological capital: Measurement and relationship with performance and satisfaction. Pers. Psychol. 2007, 60, 541-572. [CrossRef]

34. Choi, W.; Noe, R.; Cho, Y. What is responsible for the psychological capital-job performance relationship? An examination of the role of informal learning and person-environment fit. J. Manag. Psychol. 2019, 35, 28-41. [CrossRef] 
35. Russo, G.; Pires, C.A.; Perelman, J.; Goncalves, L.; Barros, P.P. Exploring public sector physicians' resilience, reactions and coping strategies in times of economic crisis; findings from a survey in Portugal's capital city area. BMC Health Serv. Res. 2017, 17, 207. [CrossRef] [PubMed]

36. Vagni, M.; Maiorano, T.; Giostra, V.; Pajardi, D. Hardiness, stress and secondary trauma in Italian healthcare and emergency workers during the COVID-19 pandemic. Sustainability 2020, 12, 5592. [CrossRef]

37. Geurts, S.; Taris, T.W.; Kompier, M.; Dikkers, J.; Van Hooff, M.; Kinnunen, U.M. Work-home interaction from a work psychological perspective: Development and validation of a new questionnaire, the SWING. Work Stress 2005, 19, 319-339. [CrossRef]

38. Spreitzer, G.M. psychological empowerment in the workplace-Dimensions, measurement, and validation. Acad. Manag. J. 1995, 38, 1442-1465. [CrossRef]

39. Montani, F.; Courcy, F.; Giorgi, G.; Boilard, A. Enhancing nurses' empowerment: The role of supervisors' empowering management practices. J. Adv. Nurs. 2015, 71, 2129-2141. [CrossRef]

40. Chen, G.; Smith, T.A.; Kirkman, B.L.; Zhang, P.; Lemoine, G.J.; Farh, J. Multiple team membership and empowerment spillover effects: Can empowerment processes cross team boundaries? J. Appl. Psychol. 2019, 104, 321. [CrossRef]

41. Pigeon, M.; Montani, F.; Boudrias, J. How do empowering conditions lead to empowered behaviours? Test of a mediation model. J. Manag. Psychol. 2017, 32, 357-372. [CrossRef]

42. Ugwu, F.O.; Onyishi, I.E.; Rodriguez-Sanchez, A.M. Linking organizational trust with employee engagement: The role of psychological empowerment. Pers. Rev. 2014, 43, 377-400. [CrossRef]

43. Li, Y.; Wei, F.; Ren, S.; Di, Y. Locus of control, psychological empowerment and intrinsic motivation relation to performance. J. Manag. Psychol. 2015, 30, 422-438. [CrossRef]

44. Moncada, S.; Llorens, C.; Navarro, A.; Kristensen, T.S. ISTAS21: Versión en lengua castellana del cuestionario psicosocial de Copenhague (COPSOQ). [ISTAS21: The Spanish version of the Copenhagen psychosocial questionnaire (COPSOQ)]. Arch. Prev. Riesgos Labor. 2005, 8, 18-29.

45. Kim, J.; Kim, H.; Lacey, R.; Suh, J. How CSR impact meaning of work and dysfunctional customer behavior. J. Serv. Theory Pract. 2018, 28, 507-523. [CrossRef]

46. Sun, J.; Lee, J.W.; Sohn, Y.W. Work context and turnover intention in social enterprises: The mediating role of meaning of work. J. Manag. Psychol. 2019, 34, 46-60. [CrossRef]

47. Van der Wal, Z. Being a public manager in times of crisis the art of managing stakeholders, political masters, and collaborative networks. Public Adm. Rev. 2020. [CrossRef] [PubMed] 